\title{
Las sentencias judiciales comos actos correctores del sistema democrático
}

\section{Patricio A. Maraniello}

\section{Resumen}

Muchas veces se ha dicho que los jueces no representan al pueblo y por lo tanto sus decisiones son contramayoritarias o anti-democráticas. Encuentran como fundamento en el hecho de que no son elegidos democráticamente, sino por un procedimiento técnico constitucional complejo, y en consecuencia podría pensar que sus sentencias no son democráticas. Como atenuante podría considerarse el hecho de que si bien el pueblo no interviene en las decisiones judiciales, en el proceso de designación de un magistrado participan sus representantes, como lo ha sostenido la Corte de Justicia Argentina en el caso "Rizzo", por el cual fijo la pauta donde los jueces son elegidos en forma indirecta por el pueblo. En la doctrina norteamericana existen tres propuestas centrales para resolver la dificultad mayoritaria, y una sola para disolverla. En la primera se encuentra la llamada fundacionalista de derecho por Roland Dworkin; en la segunda propuesta, desarrollada por John Hart Ely, la intitulada "interpretativistas"; la tercera y última es la que Stephen Holmes llamó la elección social, que se basa en la "estrategia del precompromiso". En cambio, existe una sola postura para disolverla que es la de Bruce Ackerman, basada en una teoría democrática dualista distinguiendo entre "política normal" y "política constitucional". Finalmente, hemos desarrollado nuestra posición que se acerca a la última postura, en el cual no resulta necesario ningún justificativo ni en la legitimidad democrática de los jueces ni en sus decisiones, pues en realidad los jueces tienen como función democrática su perfeccionamiento al incluir a las minorías insulares.

Palabras claves: el rol del juez; legislación negativa; teoría democrática dualista

\section{Abstract}

It has often been said that judges do not represent the people and thus their decisions

\section{Acerca del autor}

Presidente de la Asociación Argentina de Justicia Constitucional; Miembro Fundador Titular y Vicepresidente de la Asociación Mundial de Justicia Constitucional. Correo eletrónico: pmaraniello@gmail.com

2. Conferencia brindada en el IV Congreso de Derecho Procesal Constitucional Colombiano", celebrado en Santa Marta, Colombia, entre los días 22, 23 y 24 de mayo de 2013. 
are counter majoritarian or anti-democratic. Found as based on the fact that they are not democratically elected, but by a complex technical procedure constitutional, and therefore could be considered as its judgments are not democratic. In mitigation could be considered the fact that while people do not inter-comes in judicial decisions in the process of appointing a judge involved their representatives, as it has sustained the Court of Justice of Argentina in the "Rizzo" where I set the pattern where judges are elected indirectly by the people. In the American doctrine there are three main proposals to resolve the majority difficulty, and one to dissolve. Within the first Roland is Dworkin called foundationalist of law, the second proposal, developed by John Hart Ely, is the "interpretivist. The third and last is what Stephen Holmes called social choice, which is based on the "precommitment strategy." Instead, there is only one position to dissolve that is Bruce Ackerman, democratic theory based on a dualistic distinction between "normal politics" and "constitutional politics". Finally, we have developed our position approaching the last stance, where no justification necessary nor democratic legitimacy of judges or their decisions, because in reality the judges have the democratic function their execution to include the insular minorities.

Keyword: the role of the judge; negative legislation; dualistic democratic theory;

Artigo recebido em 29 de agosto de 20I4. Aceito para publicação em 3 de novembro de 2014 .

\section{Introducción}

Si decimos que el Estado somos todos, y no el rey, como sostenía Luis XIV - rey de Francia -, cuando un juez resuelve una petición presentada por uno o varios ciudadanos, ante la vulneración de un derecho, no parece que lo hiciera en representación de todos o de una gran mayoría del pueblo.

Si tenemos en cuenta que los jueces no son elegidos democráticamente, sino por un procedimiento técnico constitucional complejo, podría considerarse entonces que sus sentencias no son democráticas.

Como atenuante podría considerarse el hecho de que si bien el pueblo no interviene en las decisiones judiciales, en el proceso de designación de un magistrado participan sus representantes. Según los artículos 99, inc. $4^{\circ}$ y 114 de la Constitución Argentina, la elección de los jueces de la Corte Suprema de Justicia de la Nación la realiza el Poder Ejecutivo con acuerdo - público - del Senado. Mientras que los jueces de los tribunales inferiores son seleccionados por el Poder Ejecutivo de una terna confeccionado por un órgano especializado (Consejo de la Magistratura), que 
posteriormente serán aprobados por la Cámara de Senadores de la Nación.

Dicha respuesta no resulta el final de la cuestión, sino el inicio de varios interrogantes a desentrañar, por ejemplo: 1) ¿El Consejo es político o jurídico? Si es político no puede ser parte del Poder Judicial, y si es jurídico, no pueden ser políticos los que lo compongan; 2) ¿es necesario que el Presidente y el Senado vuelvan a actuar cuando ya tienen representación en el Consejo de la Magistratura?; 3) ¿por qué no participa la Cámara de Diputados?

Si bien éstos son interrogantes muy importantes por resolver, en este trabajo desarrollaremos tan sólo una problemática que ha fascinado en las últimas décadas a los teóricos constitucionales; nos referimos al rol del juez dentro del sistema democrático del Gobierno. Atento a que en reiteradas oportunidades los magistrados se ven cuestionados por sectores doctrinarios quienes consideran que sus decisiones son contramayoritarias.

\section{Democracia}

\section{I.I. Concepto}

La palabra democracia proviene del latín tardío democratia y ésta, del griego $\delta \tilde{\eta} \mu$ o (dếmos, que puede traducirse como "pueblo") у кра́ $\tau о \varsigma$ (krátos, que puede traducirse como "poder"). Sin embargo la significación etimológica del término es mucho más compleja. El término "demos" parece haber sido un neologismo derivado de la fusión de las palabras demiurgos (demiurgi) y geomoros (geomori). El historiador Plutarco señalaba que los geomoros y demiurgos eran junto a los eupátridas las tres clases en las que Teseo dividió a la población libre del Ática (adicionalmente la población estaba integrada también por los metecos, esclavos y las mujeres). Los eupátridas eran los nobles; los demiurgos los artesanos y los geomoros eran los campesinos. Estos dos últimos grupos, "en creciente oposición a la nobleza, formaron el demos".3 Textualmente entonces, "democracia" significa "gobierno de los artesanos y campesinos", excluyendo del mismo expresamente a los esclavos y a los nobles.

En el siglo V a. de C., durante el gobierno del estratega Pericles, surgió en Atenas un régimen político basado en decisiones populares. Los ciudadanos se reunían en la ekklesia 'asamblea popular' 
para deliberar y decidir sobre las grandes cuestiones del gobierno. Sin embargo, la mayoría de los habitantes de Atenas eran esclavos o metekos 'extranjeros', y los ciudadanos que participaban efectivamente en la vida política ateniense no pasaban del diez por ciento de la población.

La democracia resurgió en Europa durante la Edad Media en lugares aislados, como en los cantones suizos y en algunas repúblicas alemanas o italianas, y el prestigio del término se fue fortaleciendo con el ascenso gradual de la burguesía.

\section{I.2. Características}

Democracia es un sistema político en el cual el pueblo ejerce el gobierno directamente o a través de la elección de representantes. La tendencia reciente a manipular este concepto de democracia reduciéndolo a su expresión "electoral" va llevando a la desnaturalización de su propia esencia, pues si un político es elegido en elecciones libres y generales en dichas elecciones no termina la democracia, por el mandato que fuera otorgado por la mayoría, sino todo lo contrario. En un sistema presidencialista el presidente no debe adueñarse de todas las decisiones políticas del pueblo, donde nadie puede obstaculizar sus actos de gobierno hasta las próximas elecciones. En el caso que ello ocurra hemos transformado a la democracia en autocracia ${ }^{2}$ donde la autoridad recae sobre una sola persona.

En una democracia el poder no lo tiene ni un gobernante ni la mayoría que lo elige. Si vemos la esencia de la democracia, no es la todopoderosa mayoría sino en el compromiso constante entre grupos representados en el parlamento por la mayoría y la minoría y por ende la paz social, la justicia constitucional aparecen un instrumento propio de las minorías para impedir que viole inconstitucionalmente sus intereses jurídicamente protegidos y para oponerse,

2. Autocracia es un concepto político. El término procede del griego autos (uno mismo) y kratos (gobierno o poder). Designa al sistema de gobierno cuya autoridad recae sobre una sola persona sin ningún límite: el autócrata (el que gobierna por sí mismo). 
por esta vía, en último análisis, a la dictadura de las mayorías, que no es menos peligrosa para la paz social que aquella de la minoría. ${ }^{3}$

Por todo ello, podemos encontrar dos falacias significativas que ostentan los demócratas electorales. Por un lado, es un error considerar que la única legitimidad posible dentro de la democracia es el sufragio universal, como si la democracia se redujera a las elecciones, a la representación en las asambleas, o a la lógica de las mayorías. Y por otro lado, encontramos la falacia según la cual la voluntad de los representantes y los representados son una sola persona e indisoluble sin que exista divergencia entre ellos, olvidando la acelerada crisis de representación que está viviendo la mayoría de los sistemas políticos, que muestran que la divergencia no solo es posible sino que, sin duda alguna, una realidad.

Según Smith 4 la "democracia electoral” es aquella que se reduce a la existencia de elecciones libres y justas. Es decir, que se encuentra centrada exclusivamente en el componente electoral de la democracia política. No se refiere a la vida democrática, en otras palabras, ni a la protección de las libertades y derechos de los ciudadanos, ni el desempeño de las políticas públicas.

Esto nos lleva a distinguir diferentes significados de democracia. Arnold Bretch ${ }^{5}$ ha distinguido los siguientes usos contemporáneos del término:

- D1= M: Democracia entendida como gobierno de la mayoría, reconociéndosele a esta la capacidad para decidir sobre cualquier aspecto en una u otra forma.

- $\mathrm{D} 2=\mathrm{DH}+\mathrm{TI}+\mathrm{M}$ : Democracia caracterizada por el reconocimiento de los Derechos Humanos, existencia de un Tribunal Independiente (exentos de interferencias del PE y el PL), gobierno de la mayoría, el que no puede desnaturalizar los Derechos Humanos ni suprimir los Tribunales Independientes. Este es el uso del término en el lenguaje occidental.

3. Rincon Salcedo, La soberanía interpretativa de los Tribunales Constitucionales: Análisis desde la perspectiva del constitucionalismo popular, 2008.

4. Smith, Los ciclos de democracia electoral en América Latina 1900-2000, 2004.

5. Citado por Gomez, El control de constitucionalidad en un sistema democrático, LL suplemento de derecho constitucional, p. 3, may. 2013. 
- $\mathrm{D} 3=\mathrm{BG}+\mathrm{I}$ : Democracia entendida como promoción efectiva del Bienestar General y de la Igualdad, cuya realización puede corresponder, si fuere preciso, a una vanguardia del pueblo, con formación específica -partido. Es el uso del término Democracia en los países comunistas.

Del principio de la inviolabilidad de la persona humana se infiere ciertos derechos que, como dice Ronald Dworkin ${ }^{6}$, imponen un límite o umbral a la persecución de los bienes colectivo. Este mismo autor sostiene que la teoría constitucional sobre la cual se basa el gobierno de los EEUU no es una simple teoría mayoritaria. La constitución, y particularmente el "Bill of Rights", está destinada a proteger a los ciudadanos, individualmente y en grupo, contra ciertas decisiones que podría querer tomar una mayoría de ciudadanos, aun cuando esa mayoría actué siguiendo lo que para ella es el interés general o común. Si alguien tiene derecho a algo, está mal que el gobierno se lo niegue, aunque negárselo favoreciera al interés general.

\section{La Corte Suprema como "estructura de gobierno" de la Constitución}

Según lo ha dicho reiteradamente la Corte de Justicia argentina, las sentencias constituyen una unidad lógico-jurídica, cuya parte dispositiva no es sino la conclusión final y necesaria del análisis de los presupuestos fácticos y jurídicos efectuados en su fundamentación ${ }^{7} \mathrm{o}$, en otros términos, es un todo indivisible en cuanto a la recíproca integración de su parte dispositiva con los fundamentos que la informan ${ }^{8}$.

Si bien las sentencias de la Corte sólo deciden los procesos concretos que le son sometidos, sus sentencias resultan obligatorias para casos análogos, y los jueces inferiores tienen el deber moral de conformar sus decisiones a esa jurisprudencia, salvo que proporcionen nuevos argumentos que justifiquen modificar la posición allí adoptada ${ }^{9}$

\footnotetext{
6. Dworkin, Los derechos en serio, 1995, p. 211.

7. Fallos 306:2173.

8. Fallos 311:509 y 2120.

9. Fallos 318:2060 y sus citas. CSJN in re "Papelera Pedotti SA s/infracción a la Ley 23.771", del 11 de septiembre de 2007.
} 
La Constitución argentina contiene normas redactadas en términos muy generales, pero cuyas consecuencias son variadas y precisas; expresiones como usar y disponer de su propiedad o bienestar general han sido los fundamentos para decisiones que han definido la extensión de los derechos individuales.

Lo que caracteriza a estas normas tan generales es que delegan la autoridad para definir su contenido a las personas que administran su aplicación, es decir, a los jueces. Podemos entonces describir a la Corte Suprema como el agente de la presente generación, si bien limitado por el texto de la Constitución, para hacer cumplir un contrato social que nos une en una sociedad de convivencia. Es decir, que dicha Corte cumple con esta función antes que como el agente de los constituyentes. Esto último no sería realista porque los constituyentes históricos han muerto y las instrucciones que dejaron son extremadamente vagas; aun los textos modernos pierden actualidad con el paso del tiempo. Existe, por lo tanto, un incentivo muy débil para ser un agente fiel del pasado ${ }^{10}$.

El análisis de los incentivos judiciales nos lleva a creer que la estabilidad de los jueces en su empleo y la integridad de su salario tienden a reducir la función del interés propio en la toma de decisiones. Podemos entonces preguntarnos por qué confiaríamos en la protección que nos brindan los jueces y qué incentivos tendrían ellos para apoyar nuestras demandas, antes que las de la mayoría que es generalmente más poderosa ${ }^{11}$. Al mismo tiempo ¿no deberían las minorías concentrarse en el proceso legislativo donde los grupos de interés, que invariablemente son grupos minoritarios, tienen éxito influyendo en la legislación? La respuesta no puede ser definitiva, pero la estabilidad judicial, tanto en el cargo como en el salario, les permite dar soluciones independientes de la influencia política, y en este caso pueden proteger a las minorías "discretas e insulares" que no tienen protección en el proceso legislativo. La independencia es la principal fuente de legitimación del control judicial de la legislación ${ }^{12}$.

10. Sola, Derecho Constitucional, 2006.

11. La función judicial en la protección de las minorías "difusas o insulares" fue establecida en la nota n. 4 en el voto del Chief Justice Harlan Stone en el caso "U.S. vs. Carolene Products", y también analizada en la obra de Ely, 1980.

12. Sola, op. cit. 
Utilizar la analogía de un contrato de largo plazo para definir la Constitución no supone considerar las constituciones como similares al consentimiento estricto que dos adultos adecuadamente informados prestan al incorporarse a un contrato. Todo ello en gran medida debido a que aquella no es ratificada por el voto popular y que los votantes hubieran tenido una información fragmentaria y que no hubieran llegado a una solución unánime. Como ciudadanos apoyamos la Constitución porque es mejor que la anarquía o la dictadura. Pero la aquiescencia no es necesariamente consentimiento, y podemos decir que si bien la analogía del contrato es útil, la Constitución no es estrictamente una. Ello no impide que los jueces utilicen el modelo del contrato social para interpretar al Estado constitucional.

\section{La legislación negativa}

La terminología se desprende del desarrollo realizado por Kelsen en oportunidad de diseñar el sistema de control de constitucionalidad de la República Federal Alemana que atribuía al tribunal constitucional la naturaleza de legislador negativo. Deseamos puntualizar que la expresión en análisis padece de un defecto importante dado por la gran carga emotiva que porta y que adopta un carácter negativo, en atención a que en tal contexto es indiscutidamente disvalioso considerar que un órgano, en este caso el Tribunal Superior de Justicia, pueda ejercer funciones que competen por definición a la legislatura.

Según Raúl Ferreyra (1997) la carga emotiva de las expresiones lingüísticas perjudica su significado cognoscitivo, favoreciendo su vaguedad, puesto que si una palabra funciona como una condecoración o como un estigma, la gente va manipulando arbitrariamente su significado para aplicarlo a los fenómenos que acepta o repudia. De este modo, las definiciones que suelen dar las palabras con carga emotiva son "persuasivas", según la terminología de Stevenson, puesto que están motivadas por el propósito de orientar las emociones, favorables o desfavorables, que provoca en los oyentes el empleo de ciertas palabras, hacia objetos que se quiere encomiar o desprestigiar ${ }^{13}$.

13. Ferreyra, La Constitución de la Ciudad Autónoma de Buenos Aires, 1997, p. 160. 
En atención a ello, resulta, pues, evidente que la expresión en análisis, lejos de ser neutral, se encuentra cargada de emotividad, transmitiendo una valoración negativa, por lo que preferimos no utilizarla para referenciar el sistema de control concentrado. Es que no se trata, por lo demás, de una "legislación negativa", ya que ello implicaría una contradicción lógica. La legislación es, por definición, un acto de creación de disposiciones normativas, ergo, mal podría hablarse de legislación (acto de creación) negativa (negación de la legislación), ya que en sí misma esta función implica excluir del sistema jurídico una norma, por lo que no podría ser, al mismo tiempo, creación y exclusión o derogación. Cuando analizamos el ejercicio de la función de controlar la correspondencia y coherencia con la respectiva Ley Fundamental de tales disposiciones —que sí son creación del órgano legisferante- por el órgano judicial, y que se limita a "depurar" el sistema, excluyendo de este aquellas normas que resultan ser incompatibles con la norma fundamental de la Ciudad así como de la Federal, no podemos hablar de "legislación negativa"14.

En la Argentina este instituto, si bien se encuentra regulado en varias provincias, aparece receptado en forma más explícita en el art. 113 , inc. $2^{\circ}$ de la Constitución de la Ciudad de Buenos Aires; allí se establece que es competencia del Tribunal Superior de Justicia conocer:

originaria y exclusivamente en las acciones declarativas contra la validez de leyes, decretos y cualquier otra norma de carácter general emanada de las autoridades de la Ciudad, contrarias a la Constitución Nacional o a esta Constitución. La declaración de inconstitucionalidad hace perder vigencia a la norma salvo que se trate de una ley y la Legislatura la ratifique dentro de los tres meses de la sentencia declarativa por mayoría de los dos tercios de los miembros presentes. La ratificación de la Legislatura no altera sus efectos en el caso concreto ni impide el posterior control difuso de constitucionalidad ejercido por todos los jueces y por el Tribunal Superior.

Como vemos, la declaración de inconstitucionalidad equivale a una derogación y no a una anulación, es decir, opera a partir

14. Ferreyra, op.cit. p. 161. 
de dicha declaración y no en forma retroactiva. Se reconoce, en consecuencia, la validez de esa norma hasta el momento de la sentencia judicial.

Tras los pronunciamientos del Tribunal Superior de Justicia de la Ciudad de Buenos Aires, la primera inquietud que surge no puede ser otra más que pensar qué sucedió en la Legislatura ante el reenvío. Lo cierto, que de todas las declaraciones de inconstitucionalidades efectuadas por el Tribunal Superior de la Ciudad de Buenos Aires, el único - que tenemos conocimiento - que ha sido específicamente tratado fue el caso: "Gordillo, Agustín Alberto vs. GCBA (Legislatura de la Ciudad de Buenos Aires) y otro s/acción declarativa de inconstitucionalidad", del 25 de noviembre de $2003^{15}$, allí la Legislatura de la ciudad ratifico la norma.

Así, vemos cómo la Legislatura acepta implícitamente - salvo raras excepciones como la señalada - las atribuciones conferidas por la Constitución de la Ciudad de Buenos Aires a los miembros del Tribunal Superior de dicha ciudad, como algo que beneficia al sistema democrático, pues se establecen estructuras gubernativas con órganos suficientemente entrelazados que impiden que el poder se concentre en sólo uno de ellos.

\section{Las dificultades contramayoritarias}

Alexander Bickel ${ }^{16}$ se refirió a la dificultad contramayoritaria, que se sustenta -básicamente - en el siguiente enunciado: "Cuando la Suprema Corte declara inconstitucional una ley o una acción de un Ejecutivo tuerce la voluntad de los representantes del pueblo real de aquí y ahora; ejerce el control, no en nombre

15. La legislatura, en sesión del 18 de marzo de 2004 ratificó - por intermedio del dictado de la Resolución 12/2004 - las disposiciones normativas declaradas inconstitucionales meses antes por el Tribunal Superior de Justicia, por considerar que vulneraban la finalidad tenida en miras por el constituyente, plasmada en los arts. 115 y 121 CCBA, vinculada a mantener el equilibrio y asegurar una participación igualitaria de todos los sectores llamados a conformar el Consejo de la Magistratura y el Jurado de Enjuiciamiento. De este modo, la Legislatura ratifica la norma cuestionada y la deja sin el efecto erga omnes respectivo, contrariando la inconstitucionalidad articulada por el Tribunal Superior de Justicia en su sentencia.

16. Bickel citado en Mendonca y Guibourg, 2004, p. 149-50. 
de la mayoría, sino en su contra". Esta postura llega al extremo de calificar la revisión judicial como una anomalía del régimen democrático. De modo que lo que se encuentra en jaque es, ni más ni menos, la legitimidad de la que goza o no, el órgano judicial para ejercer el control de los actos y de las normas emanadas de los órganos Legislativo y Ejecutivo. El problema no se limita a los supuestos en que aquél ejerce un control concentrado, sino que abarca también a aquellos en los que lo ejerce de modo difuso, debido a que tal afirmación desconoce en absoluto la posibilidad de que este cuerpo controle los actos o decisiones de los otros órganos.

\section{La teoría constitucional norteamericana}

El constitucionalismo norteamericano desde sus inicios ha considerado al Poder Judicial un verdadero poder del Estado, sin mengua del sistema democrático. Ello puede verse en el libro El Federalista, escrito por Hamilton, Madison y Jay, en el que se afirma que:

[...] es nulo todo acto de una autoridad delegada contraria al tenor del mandato o encargo bajo el cual se ejerce. Ningún acto legislativo, por tanto, contrario a la Constitución, puede ser válido. Negar esto significaría afirmar que el agente importara más que el principal, que el sirviente es superior a su patrón: que los representantes del pueblo son superiores al pueblo mismo [...] ni en manera alguna supone tal deducción superioridad alguna del poder judicial sobre el poder legislativo. Sólo supone que el poder del pueblo es superior al de ambos; y que donde la voluntad de la legislatura, declarada en sus leyes, está en oposición a la del pueblo, declarada en la Constitución, los jueces deben regirse por ésta más bien que por aquella ${ }^{17}$.

Más contemporáneo, Bruce Ackerman ${ }^{18}$ ha considerado que la teoría constitucional norteamericana tiene tres propuestas centrales para resolver la dificultad mayoritariamente, y sólo una propuesta para disolverla.

17. Hamilton; Madison; Jay, 2001.

18. Ackerman, 1998. 


\section{I. Los fundacionalistas de derechos}

Ronald Dworkin ${ }^{19}$ considera la subordinación de la democracia a ciertos derechos fundamentales que están explícita o implícitamente relacionados con la Constitución Nacional. Esta posición es llamada por el autor citado como fundacionalista de derecho, en que se subordina la democracia a ciertos derechos fundamentales como la libertad y la igualdad ${ }^{20}$. Ésta es una posición de epistemología moral y metaética, antes que de adjudicación.

En esta teoría se especifica que la falta de representatividad de los jueces está compensada, sino neutralizada, por su función mediadora entre la democracia y los derechos; el juez es el especificador de derechos, de modo que su rol en el proceso democrático es decisivo como formulador último de aquéllos, sin importar que su formulación signifique la invalidación de decisiones mayoritarias.

\subsection{El ethos democrático}

La segunda propuesta desarrollada por John Hart Ely es la llamada "interpretativista", por la cual subordina el control de constitucionalidad al espíritu y a los valores, al ethos democrático. El mencionado autor desarrolla una idea autosuficiente constitucional en la interpretación, que puede caracterizarse tanto en términos de una versión amplia de constructivismo judicial o de una versión moderada de anticonstructivismo ${ }^{21}$.

La reconciliación entre adjudicación constitucional y el Gobierno democrático se predica sobre la base de tres argumentos:

1. Las premisas de la Constitución democrática.

2. La estructura constitucional se ocupa claramente, por un lado, de la justicia procedimental en la resolución de disputas individuales, y por el otro, de garantizar una amplia participación en los procesos de gobierno.

19. Dworkin, Law's Empire, 1988.

20. Dworkin, ob. cit.

21. Ely, Democracy and Distrust, 1981. 
3. El conocimiento especializado de los jueces los capacita para supervisar cuestiones de justicia procedimental ${ }^{22}$.

El conocimiento experto, sumado al aislamiento político de los magistrados, convierte a la judicatura en la institución más adecuada para arbitrar en conflictos atinentes al proceso político.

\subsection{Estrategia del precompromiso}

La tercera y última es la que Stephen Holmes ${ }^{23}$ llamó la elección social, que se basa en la estrategia del precompromiso, en el cual la voluntad de la mayoría se realiza mejor imponiendo la adhesión a sus aspiraciones y compromisos a largo plazo, en lugar de permitir la satisfacción de deseos transitorios o creencias indebidamente fundadas ${ }^{24}$.

De acuerdo con esta posición, invalidar una pieza de legislación mayoritaria puede ser consistente con la regla de la mayoría en la medida en que la estrategia del precompromiso se encuentre debidamente limitada, por ejemplo, aplicándosela sólo de manera intergeneracional, en lugar de presuponer la problemática tesis de que el pueblo sea una entidad constante a través de distintas generaciones; debe referirse a valores o principios específicos, para evitar que se convierta en una mera invitación a que los tribunales desplacen las preferencias políticas de la legislatura bajo el disfraz del precompromiso. El compromiso sólo puede ser efectivizado en la medida en que las circunstancias que lo inspiraron no hayan cambiado tan dramáticamente que lo priven de su fuerza vinculante.

\subsection{El dualismo normativo}

Por su parte, Ackerman propone disolver, antes que resolver, la dificultad contramayoritaria; el control de constitucionalidad no

22. Ely, ibídem.

23. Holmes, Precommitment and the Paradox of Democracy, citado por Elster y Slagstad, Constitutionalism and democracy, 1988, p. 195.

24. Se recuerda el ejemplo clásico de Ulises pidiendo ser atado al mástil del barco para evitar la tentación del canto de la sirena. 
entraña un problema fundamental de legitimidad ya que, lejos de oponerse a constituir una alternativa a la práctica democrática, es en sí mismo una forma de ésta ${ }^{25}$.

Ackerman critica a los partidarios del fundacionalismo de derechos, a los interpretativistas y a los teóricos de la elección popular, porque todos ellos incurren en el mismo error, concebir la práctica constitucional norteamericana en términos monistas.

La historia y la práctica constitucionales en EE. UU. son más adecuadamente caracterizadas por una distinción entre "política normal" y "política constitucional”, es decir, por una teoría democrática dualista y no monista. El rasgo distintivo de la política constitucional está dado por juicios populares considerados acerca de los derechos de los ciudadanos y los intereses permanentes de la comunidad.

\section{Doctrina nacional}

Empero, Raúl Eugenio Zaffaroni ${ }^{26}$ articula una postura sumamente interesante y explica que "una institución no es democrática únicamente por provenir de elección popular [...] una institución es democrática cuando es funcional para el sistema democrático, es decir, cuando es necesaria para su continuidad, como sucede con el judicial". Dicho de otra manera, el elemento determinante de la correspondencia de una institución con la democracia no es exclusiva ni excluyentemente la elección por el voto directo del pueblo o de la ciudadanía, sino antes bien la funcionalidad de dicha institución para los objetivos o el desarrollo del sistema democrático.

Por otro lado, no encuentra asidero constitucional alguno la postura contramayoritaria reseñada en líneas precedentes, en cuanto a través de ésta se justificaría que los órganos que gozan de representatividad pueden dictar actos o emitir disposiciones normativas que se encontrarían plenamente vigentes y regirían para toda la comunidad, pese a que - sin embargo - podrían resultar repugnantes a la Ley Fundamental que, en definitiva, es la última voz del pueblo; claro ejemplo de la afirmación precedente está dado por la posibilidad de que el máximo tribunal que compone el órgano judicial local declare

25. Ackerman, We the people: Foundations, 1991, p. 240.

26. Zaffaroni, 1994, p. 41. 
la inconstitucionalidad de una norma por resultar repugnante a la Constitución local o a la Constitución Federal, y que, no obstante, ella deba ser acatada por la ciudadanía por haber sido ratificada por la Legislatura ${ }^{27}$.

Tal afirmación implicaría desconocer en absoluto aquel cúmulo de declaraciones, derechos y garantías que surgen como expresión última del pueblo y que resultan ser, en consecuencia, los que reúnen mayor representatividad; implica desconocer el contrato social primero, aquel pacto que contiene los principios básicos respecto de los que hay un consenso unánime, que representa por igual a mayorías y minorías, resguardando los derechos de estas últimas como los de las primeras. Dicha postura implica, en definitiva, sostener la dictadura de la mayoría o - peor aún - implica que la mayoría deba otorgar un poder irrevocable e irrestricto a aquellos que se supone la "representan", quedando a merced de un grupo de individuos que cuentan con facultades tales que les permiten adoptar cualquier decisión, asegurando la impunidad de no quedar aquéllas sometidas posteriormente a control alguno a cargo de un órgano independiente, como es el judicial.

Por su parte, Bidart Campos expresa que "el efecto derogatorio es solamente eso: un 'efecto' de la declaración de inconstitucionalidad, y que la 'naturaleza' de la función que cumplen los órganos que emiten tal declaración no se ha de confundir con el efecto que ella surte [...]. El tribunal que con su declaración de inconstitucionalidad anula o deroga una norma general, ejerce función jurisdiccional y no legislativa..." 28 .

\section{Caso "Rizzo"}

La Corte Suprema de Justicia de la Nación, el 18 de junio de 2013, ha dictado sentencia en la causa "Rizzo Jorge Gabriel (apoderado Lista 3 Gente Derecho) s/acción de amparo vs. Poder Ejecutivo Nacional - Ley 26.855 - medida cautelar”, en el ámbito del recurso extraordinario por salto de instancia que fuera deducido por el Estado Nacional. En el fallo dictado en esa causa, el Alto Tribunal resolvió:

27. Zaffaroni, ob. cit.

28. Campos, El derecho de la Constitución y su fuerza normativa, 2003, p. 403. 
$1^{\circ}$ ) Declarar la inconstitucionalidad de los artículos $2^{\circ}, 4^{\circ}, 18$ y 30 de la Ley 26.855 y del Decreto 577/13.

$\left.2^{\circ}\right)$ Declarar la inaplicabilidad de las modificaciones introducidas por la Ley 26.855 con relación al quórum previsto en el artículo $7^{\circ}$, al régimen de mayorías y a la composición de las comisiones del Consejo de la Magistratura, en conformidad con lo previsto en el artículo 29 de dicha ley.

$\left.3^{\circ}\right)$ Disponer que en los puntos regidos por las normas declaradas inconstitucionales e inaplicables, mantendrá su vigencia el régimen anterior previsto en las leyes 24.937 y sus modificatorias 24.939 y 26.080 .

$4^{\circ}$ ) Dejar sin efecto la convocatoria a elecciones para los cargos de consejeros de la magistratura representantes de los jueces de todas las instancias, de los abogados de la matrícula federal y de otras personas del ámbito académico y científico establecida en los artículos 18 y 30 de la Ley 26.855 y en los artículos $1^{\circ}, 2^{\circ}, 3^{\circ}$ y concordantes del Decreto $577 / 13$.

$5^{\circ}$ ) Aclarar que lo resuelto no implica afectación alguna del proceso electoral para los cargos de diputados y senadores nacionales establecido en el Decreto 501/13.

$6^{\circ}$ ) Imponer las costas a la recurrente (artículo 68 del Código Procesal Civil y Comercial de la Nación).

Al respecto cabe destacar que si bien las decisiones de la Corte Suprema se circunscriben, como es obvio, a los procesos concretos que le son sometidos a su conocimiento y sus fallos no son obligatorios para casos análogos ${ }^{29}$, no cabe desentenderse de la fuerza moral que emana de su carácter supremo, en razón de la autoridad institucional de los fallos del Alto Tribunal en dicho carácter como intérprete de la Constitución Nacional y de las leyes, de lo cual deriva el consecuente deber de someterse a sus precedentes ${ }^{30}$.

29. Fallos 25:365; 307:1094; 315:2386; 332:616 entre otros.

30. Fallos 315:2386; 320:1660; 1821; 321:2294; 3201; del dictamen de la Procuración General, al que remitió la Corte Suprema, en Fallos 331:1664; 332:1488 entre otros. 
Ello es así, en tanto la eficacia y la uniformidad del control de constitucionalidad ejercido por los jueces también requiere la existencia de un tribunal supremo especialmente encargado de revisar las decisiones dictadas al respecto. En el régimen de la Constitución, tal órgano no es otro que la Corte Suprema de Justicia de la Nación. De ahí que haya sido expuesto, reiteradamente y desde los albores de nuestra definitiva organización, que ella es el intérprete y la salvaguarda final de la Constitución Nacional y de los derechos y garantías en ésta contenidos ${ }^{31}$.

Ahora bien, yendo a la cuestión medular de este comentario, se puede sostener que existe y ha existido una reiterada discusión que se centraliza en la consideración de los integrantes del Poder Judicial como órganos contramayoritarios en lo que hace a su designación, si se compara con los otros poderes del estado (Poder Legislativo y Poder Ejecutivo) que son elegidos por sufragio popular.

Si bien es cierto que todo el sistema republicano se nutre del sufragio universal, ello no significa que en una democracia todo debe ser elegido o designado por el voto de la ciudadanía ${ }^{32}$.

Ante ello, la Corte Suprema de Justicia de la Nación, en el considerando 27 del caso "Rizzo", ha realizado una interesante opinión en la cual ha considerado que:

[...] el Poder Judicial tiene la legitimidad democrática que le da la Constitución Nacional, que no se deriva de la elección directa. En la Asamblea Constituyente de 1853/60 expresamente se decidió que los jueces fueran elegidos por el pueblo pero en forma indirecta, al ser nombrados por el Poder Ejecutivo con acuerdo del Senado; esquema que - además - fue ratificado por la reforma de 1994. En consecuencia, resulta consistente que los consejeros, como miembros de un órgano que integra el Poder Judicial de la Nación, sean elegidos en forma indirecta, de la misma manera que los jueces [...].

Aquí se ha realizado una distinción entre elecciones democráticas directas e indirectas, ubicando en esta última opción a los

31. Fallos 1:340; 33:162; 311:2478; del dictamen de la Procuración General, al que remitió la Corte Suprema, en Fallos 330:4104 entre otros.

32. Bianchi, Crónica de una inconstitucionalidad manifiesta, La Ley, 26 de marzo de 2013, p. 4. 
integrantes del Poder Judicial y, en consecuencia, las sentencias judiciales deben considerarse como decisiones mayoritarias indirectas, además de estimarse sus efectos como correctores del sistema democrático.

Pues las minorías insulares que no tienen posibilidad de ser consideradas en decisiones trascendentales del país, ya que éstas son tomadas por las mayorías, tienen en el Poder Judicial, en cada caso concreto, la oportunidad de hacer que sus derechos sean respetados.

Finalmente, el Poder Judicial como órgano corrector del sistema democrático obtiene, a partir del caso "Rizzo", legitimidad constitucional que le permitirá tener una función primordial en el tramado constitucional sin cuestionamiento, y que surge precisamente en la forma de elección democrática indirecta de todos los jueces en un procedimiento complejo institucional, en los cuales participan el Consejo de la Magistratura Nacional y los poderes políticos del Estado (Poder Ejecutivo y Poder Legislativo).

Sea todo ello un punto final al añejo enfrentamiento, que una parte de la doctrina consideraba, entre la democracia y los jueces. Como lo ha sostenido Fayt, "[...] en la democracia constitucional la sustentación del poder político no reside exclusivamente en la soberanía popular sino, también, en el imperio de la ley [...]”.

\section{Nuestra posición}

Como es sabido, la ley es por excelencia la decisión mayoritaria del sistema democrático, si bien su creación se realiza a través de los representantes del pueblo (Poder Ejecutivo y Poder Legislativo). Sin embargo, con ello no finaliza la cuestión en debate, pues para poder ingresar al sistema jurídico requiere su compatibilidad con la Constitución; a esto se llama "control de constitucionalidad".

Por dicho motivo consideramos que la creación de una ley reviste cierto carácter especial que consta de cinco etapas bien diferenciadas: la propuesta, la discusión, la aprobación, la ejecución y su compatibilidad constitucional (al caso concreto) ${ }^{33}$ :

33. Conferencia dictada en el Primer Congreso Colombiano de Derecho Procesal Constitucional, celebrado en la ciudad de Bogotá, el 28 de mayo de 2010. 
1. La propuesta. Puede ser del Poder Ejecutivo, del propio Poder Legislativo o del pueblo directamente; a esto se lo llama "iniciativa popular”.

2. La discusión. No puede haber reglas generales sin la opinión de los integrantes de las Cámaras legislativas y las consultas a los distintos sectores sociales involucrados (empresas, sindicatos, técnicos especializados, ONG entre muchos otros).

3. La aprobación. Una vez realizado el debate y escuchadas todas las partes involucradas, la ley se aprueba por medio de una votación, de un quórum determinado. Tanto este punto como el anterior son desarrollados en el Poder Legislativo, constituyéndose una de las dos Cámaras en iniciadora del proyecto y otra en revisora.

4. La ejecución general. Es realizada por el Poder Ejecutivo, que se encarga de promulgarla, publicarla y reglamentarla para poder mejorar su puesta en práctica.

5. La compatibilidad constitucional. Esta tarea es entera y exclusivamente del Poder Judicial; analiza en el caso concreto si la ley ha respetado los principios, derechos y garantías constitucionales.

Una situación especial ocurre con la Constitución Nacional y los tratados internacionales, en los cuales participan, además de los ya señalados, otros poderes, por ejemplo, la Convención Constituyente, en el primer caso, y los organismos internacionales (OEA, ONU etc.), en el segundo. Aunque no debemos olvidar que el Poder Legislativo también interviene en ambos casos, sea en la ley de necesidad de reforma (Constitución) o en la ley que aprueba los instrumentos internacionales (tratados internacionales) ${ }^{34}$.

Nuestra posición parte de la base de que toda norma pasa por varios ciclos transformadores, como discusión, votación, aprobación (por mayoría), ejecución, vigencia, interpretación, aplicación y compatibilidad. Por su parte, todos los poderes del Estado participan

34. Maraniello, 2012. 
en estos ciclos, cada uno dentro de su facultad exclusiva (Poder Legislativo, Poder Ejecutivo y Poder Judicial).

El concepto conocido en español como democracia tiene sus bases en el antiguo griego, y se forma al combinar los vocablos demos (que se traduce como "pueblo") y kratós (que puede entenderse como "poder" y "gobierno"). La democracia es el gobierno de la multitud (Platón) o de la mayoría (Aristóteles).

Si tenemos en cuenta que la democracia es el gobierno de todos, en ninguna democracia participan todos, sino que lo hacen a través de sus representantes (democracia representativa), pero en la actualidad muchas veces esta realidad se ve quebrantada, por la falta o crisis de representatividad que existe. Esta situación se produce tanto con la mayoría como con las minorías abandonadas y no escuchadas.

Es por ello que, justamente, las mayorías desoídas y especialmente las minorías ausentes y olvidadas ven en el Poder Judicial, a través de la presentación de sendas demandas, que sus derechos pueden ser respetados.

De este modo, las sentencias, que protegen a esa minoría desprotegida o a esas mayorías que no ven representadas, completan el ciclo democrático que se dicta para cada caso concreto por el Poder Judicial a través de sus resoluciones correctoras de las falencias enunciadas.

Esas sentencias correctoras emitidas por un juez, cualquiera fuera su instancia (primera, segunda o Corte Suprema de Justicia), lo que realmente hacen, quizás sin saberlo, es reparar las imperfecciones del sistema democrático, pues con los poderes políticos no podemos decir que la democracia se encuentra cumplida en su totalidad, sino por el contrario, se va perfeccionando cuando es examinada la protección de sus derechos en una situación particular en un caso concreto.

Porque ver al sistema democrático como se veía en el siglo VI a. C. en Atenas, donde fue utilizado por primera vez, es no ver los sistemas de gobierno en una realidad incontrastable. También debemos decir que las formas de gobierno deben aggiornarse, porque no se puede pensar un modelo de gobierno eterno, sino por el contrario, requiere que se actualice a las nuevas necesidades. De eso se trata la democracia, del gobierno de todos, pero no sólo en la participación representativa, sino en la solución absoluta para la totalidad de los ciudadanos, en que nadie se encuentre desprotegido ante normas 
inconstitucionales que dañen, desprotejan o desamparen principios, derechos y garantías constitucionales.

Es por dichas cuestiones que también se entiende como democracia al conjunto de reglas que determinan la conducta para una convivencia ordenada política y socialmente. Se podría decir que se trata de un estilo de vida cuyas bases se encuentran en el respeto a la dignidad humana, a la libertad y a los derechos de todos y cada uno de los miembros. La democracia constituye una opción de alcance social en que para la ley todos los ciudadanos gozan de libertad y poseen los mismos derechos.

\section{El experimentalismo democrático. La democracia realizada}

Como último punto, resulta relevante saber la situación actual del sistema democrático en su aspecto político-social, en que el ciudadano adquiere un nuevo rol.

El profesor brasileño, Roberto Mangabeira Unger ${ }^{35}$, en su libro $\mathrm{La}$ democracia realizada (1997), llama experimentalismo democrático a la combinación de dos esperanzas y una práctica de reflexión y de acción $^{36}$.

- La primera esperanza del demócrata, de acuerdo con el experimentalismo democrático, es encontrar el área de superposición entre:

- las condiciones del progreso práctico o material, que incluyen el crecimiento económico y la innovación tecnológica o médica, apoyada por los descubrimientos científicos. Es el desarrollo de nuestra capacidad de hacer retroceder las

35. Nacido en Río de Janeiro en 1947, Mangabeira Unger se recibió en Derecho y realizó su posgrado en Estados Unidos; comenzó a enseñar a los veinticuatro años en esa Universidad y se transformó así en uno de los profesores titulares más jóvenes en la historia de esa institución norteamericana, y ha sido el autor de polémicas tesis de teoría política, social y de Derecho Privado. Su larga permanencia en el país norteamericano le dejó como herencia un fuerte acento inglés. Desde el año pasado, Mangabeira Unger es, además, el principal ideólogo del Partido Republicano Brasileño (PRB) y Ministro de Asuntos Estratégicos de la República de Brasil.

36. Mangabeira Unger, 1997. 
coacciones de la escasez, la enfermedad, la debilidad y la ignorancia;

- las exigencias de la emancipación individual, como un modo de liberación de los individuos del influjo de los roles, las divisiones y las jerarquías sociales enquistadas, en especial cuando esta maquinaria social extrae su fuerza de la ventaja heredada y modela las posibilidades de vida de los individuos.

- La segunda, es que este trabajo responda a las necesidades y aspiraciones sentidas de los hombres y las mujeres comunes y corrientes.

- La práctica que combina estas dos esperanzas es una manipulación motivada, sostenida y acumulativa de los dispositivos de la sociedad. Una premisa de esta práctica es la relación interna entre las nociones de ideales o intereses y la reflexión sobre prácticas e instituciones.

El experimentalismo democrático afirma que las condiciones del progreso práctico y la emancipación individual pueden entrecruzarse.

La innovación experimental alimenta el predominio de los talentos y las capacidades individuales sobre los privilegios grupales.

En "El experimentalismo y la gente común" se hace hincapié en lo llamado agency, que si bien no tiene un equivalente en castellano, en el contexto de las ciencias sociales se lo utiliza para designar la capacidad de obrar de los seres humanos, que no son meros receptores de la acción, sino sus creadores (sus agentes).

Unger muestra que ni los países desarrollados ni los que se encuentran en desarrollo pueden alcanzar la celebrada síntesis de la flexibilidad económica al estilo norteamericano y la protección social al estilo europeo sin cambiar sus instituciones. En una era en que las fuerzas progresistas están marcadas por la timidez y las actitudes defensivas, la democracia realizada restaura la energía y restablece el cauce hacia la imaginación de futuros alternativos para la sociedad. De esta manera, convierte la esperanza en programa y debate de ideas. 
Luego Mangabeira Unger ${ }^{37}$, habla sobre la reconstrucción de las instituciones, aquí considera que sería conveniente refundar la democracia sobre la base de la creación de un nuevo sujeto de derecho: el individuo emergente en una democracia distinta, de bases que ya no son inamovibles; paso fundamental para tornar la economía de mercado más incluyente, más allá de políticas compensatorias y transferentes. Las bases del pensamiento del referente de la Critical Legal Studies, una de las corrientes jurídicas más controvertidas de Harvard, por sus enfoques revolucionarios, fueron expuestas en una sesión académica desarrollada el 12 de setiembre de 2009 en el Centro Argentino de Relaciones Internacionales.

Mangabeira Unger, un intelectual de vanguardia con una visión antroposófica, torna la política en esencial y la reinstala con la virtud de "hacer del ideal del individuo una forma de vida social" ${ }^{38}$.

\section{A modo de reflexión final}

Cooley sostenía que "en todo Estado soberano el Poder Legislativo es el depositario de la mayor suma de poder y es, a la vez, el representante más inmediato de la soberanía" ${ }^{39}$.

Ya en los inicios de las revoluciones constitucionales de Estados Unidos y de Francia se ha pensado en el rol del Poder Judicial y su relación con el pueblo. En el primero, siguiendo la tradición inglesa, el pueblo se vio representado por el llamado jurado que interviene en una gran parte de los juicios, mientras que en Francia el Poder Judicial no fue considerado un poder del Estado, y sus decisiones no podían ir en contra de la ley ${ }^{40}$.

Sin embargo, en las últimas décadas la dificultad contramayoritaria en los jueces ha fascinado a los teóricos constitucionales más importantes del mundo.

37. Mangabeira Unger, ob. cit.

38. Véase: www.mercosurabc.com.ar/seccion.asp.

39. CSJN in re "Doña Sara Doncel de Cook vs. Provincia de San Juan, sobre repetición de pago", sentencia del 6 de septiembre de 1929, entre muchos otros. Fallos 155:290.

40. El célebre Montesquieu, en Espíritu de las leyes, en el VI, p. 186, en referencia al Poder Judicial, dice "que de las tres potestades de que hemos hablado, la de juzgar es en cierto modo nula”. 
En pocas palabras, las diferentes teorías han querido justificar la autorización a los jueces - que no han sido elegidos popularmente y no están sujetos a la responsabilidad de dar cuenta de sus actos ante el pueblo - para invalidar la elección de ciertos cursos de acción política por parte de los legisladores elegidos democráticamente.

Ackerman ${ }^{41}$ explica que la teoría constitucionalista en EE. UU. conoce tres propuestas centrales para resolver la dificultad mayoritaria, y una sola para disolverla. Una posición diseñada por Dworkin, llamada fundacionalista de derecho en la cual se subordina la democracia a ciertos derechos fundamentales (libertad e igualdad) ${ }^{42}$. La segunda propuesta, desarrollada por Ely, es la llamada "interpretativistas", por la cual subordina el control de constitucionalidad al espíritu y a los valores, al ethos democrático ${ }^{43}$. La tercera y última es la que Holmes ${ }^{44}$ llamó la elección social, que se basa en la "estrategia del precompromiso", en que la voluntad de la mayoría se realiza mejor imponiendo la adhesión a sus aspiraciones y compromisos a largo plazo, en lugar de permitir la satisfacción de deseos transitorios o creencias indebidamente fundadas.

Por su parte, Ackerman propone disolver, antes que resolver, la dificultad contramayoritaria; el control de constitucionalidad no entraña un problema fundamental de legitimidad ya que, lejos de oponerse a constituir una alternativa a la práctica democrática, es en sí mismo una forma de ésta. La historia y la práctica constitucionales en EE. UU. son más adecuadamente caracterizadas por una distinción entre "política normal" y "política constitucional”, es decir, por una teoría democrática dualista y no monista. El rasgo distintivo de la política constitucional está dado por juicios populares considerados acerca de los derechos de los ciudadanos y los intereses permanentes de la comunidad.

Nuestra posición va en una dirección similar a la sostenida por Ackerman; encuentra que el problema contramayoritario de las sentencias judiciales no resulta ser un inconveniente, sino una forma práctica de la democracia, en el cual la ley pasa por varias etapas (discusión, votación, ejecución y compatibilidad), en las que participan todos los poderes del Estado, y el Poder Judicial precisamente se ocupa de la última parte de la etapa de la ley, corrigiendo las falencias de una democracia incompleta.

41. Ackerman, ob. cit. p. 9.

42. Dworkin, 1988.

43. Ely, 1980.

44. Holmes citado por Elster y Slagstad, 1988, p. 195. 
Y resulta de este modo, pues en general las leyes son aprobadas por la mayoría y no por las minorías vulnerables, que buscaran una respuesta a sus necesidades en el Poder Judicial, por el cual un juez a través de sus sentencias - seguramente - dará solución a sus derechos.

Finalmente, para que exista una democracia real de cualquier tipo (directa, indirecta o participativa), es necesario que se cumplan las obligaciones constitucionales, internacionales (tratados) o leyes, que regularán y protegerán la soberanía popular, la libertad y la igualdad. Las tres palabras que definen este estilo de vida representado por un Gobierno democrático escogido por los ciudadanos.

Según Dominique Rousseau (1999, p. 470), "el juez constitucional permite al pueblo verse como soberano gracias a un espejo, la Constitución - carta jurisprudencial de los derechos fundamentales que refleja al pueblo su soberanía y a los delegados electos su subordinación al soberano. La justicia constitucional hace visible, así, lo que el modelo representativo hace olvidar: poniendo la representación en representación [...]”.

\section{Referências}

ACKERMAN, B. (1998). La política del diálogo liberal. Barcelona: Gedisa, 1998.

BIDART CAMPOS, G. (2003). El derecho de la Constitución y su fuerza normativa. Buenos Aires: Ediar.

DWORKIN, R. (1988). Law's Empire. Cambridge: Harvard University Pass. [Ed. cast. El imperio de la justicia. Barcelona: Gedisa.]

ELY, J. H. (1980). Democracy and distrust: a theory of judicial review. Cambridge: Harvard University Press.

ELSTER, J.; SLAGSTAD, R. (1988). Constitutionalism and democracy. Cambridge: Cambridge University Press.

FERREYRA, R. G. (1997). La Constitución de la Ciudad Autónoma de Buenos Aires. Buenos Aires: Depalma, 1997.

HAMILTON, A.; MADISON, J.; JAY, J. (2001). El federalista. 2. ed. México, DF: Fondo de Cultura Económica.

MANGABEIRA UNGER, R. (1997). La democracia realizada. Buenos Aires: Manantial.

MARANIELLO, P. (2012). Proyectos legislativos del hábeas normas. Revista La Ley, Ciudad de Buenos Aires, n. 2, abr. 2012.

MENDONCA, D.; GUIBOURG, R. A. (2004). La odisea constitucional. Madrid: Marcial Pons. 
ROUSSEAU, D. (1999). Droit du contentieux constitutionnel. París: Montchrestien, p. 470.

SOLA, J. V. (2006). Derecho constitucional. Buenos Aires: Lexis Nexis.

SMITH, P. (2004). Los ciclos de democracia electoral en América Latina 1900-2000. Revista Política y Gobierno, v. 9, n. 2, p. 192.

ZAFFARONI, E. (1994). Estructuras judiciales. Buenos Aires: Ediar. 